Aleksandra Burdziej*

\section{Literatura jako fenomen kulturowy. 0 kulturoznawstwie Aleidy Assmann}

DOI: http://dx.doi.org/10.12775/LC.2017.044
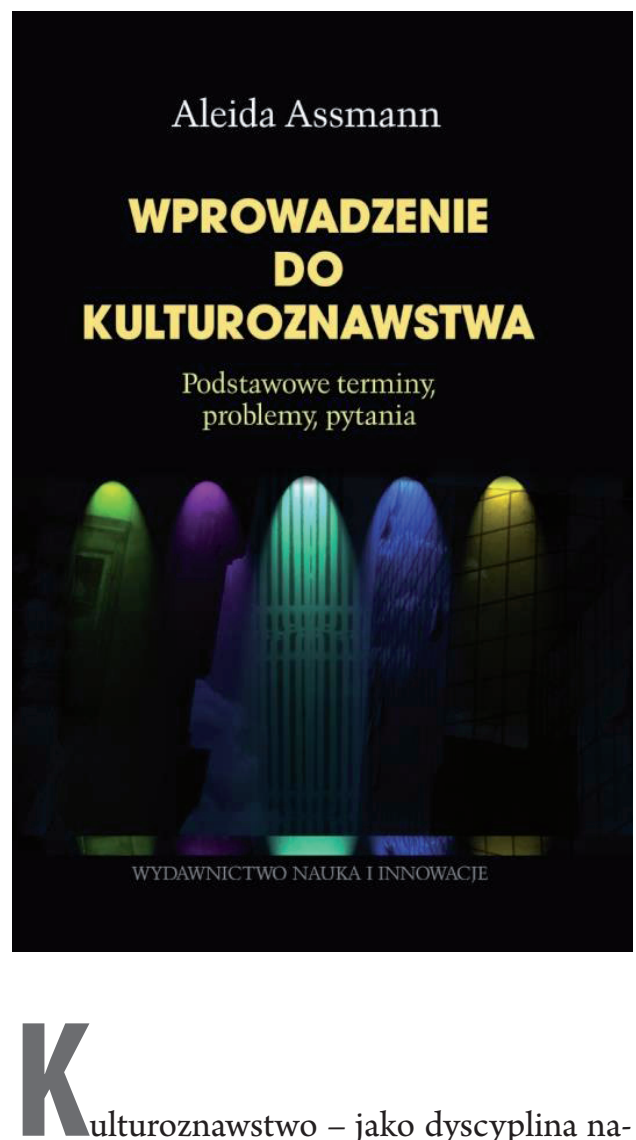

ulturoznawstwo - jako dyscyplina naukowa - było i jest w Polsce przedmiotem intensywnej dyskusji. Przyjmowane wobec niego pozycje są dosyć skrajne. Niektórzy badacze, podkreślając brak jasno określo-

* Adiunkt w Katedrze Filologii Germańskiej Uniwersytetu Mikołaja Kopernika w Toruniu. Jej zainteresowania badawcze dotyczą: niemieckojęzycznej literatury i kultury XX i XXI wieku, dyskursów wokól pamięci i tożsamości niemieckiej, stosunków polsko-niemieckich w XX i XXI wieku. E-mail: aburdziej@umk.pl. nego przedmiotu tej dziedziny bądź jego pokrywanie się z obszarami badawczymi innych dyscyplin, w ogóle kwestionują rację bytu kulturoznawstwa jako nauki. Inni próbują tę relatywnie młodą dyscyplinę, jej metody oraz obszar zainteresowań zdefiniować, dostrzegając w niej potencjał badawczy i odpowiedź na współczesne przemiany społeczno-kulturowe ${ }^{1}$. Chociaż więc dostępnych jest w Polsce szereg publikacji na temat kulturoznawstwa jako dziedziny nauki (zarówno autorów polskich, jak i zagranicznych), to przełożenie na język polski Wprowadzenia do kulturoznawstwa Aleidy Assmann jest - i powinno być - dla rodzimych kulturoznawców istotnym wydarzeniem. Pozycja ta bowiem znacząco różni się od innych wstępów do tej dziedziny nauki ${ }^{2}$, zaś sama Assmann (wraz $\mathrm{z}$ mężem, Janem Assmannem) należy już do klasyków kulturoznawstwa niemieckiego (Kulturwissenschaft) i antropologii kulturowej. Polscy badacze w języku ojczystym mogli do tej pory zapoznać się jedynie z niewielką porcją jej pracy naukowej ${ }^{3}$.

Co odróżnia propozycję Assmann od innych pozycjiztejdziedziny? Wprowadzenie do kulturoznawstwa niemieckiej badaczki charakteryzuje przede wszystkim pominięcie ustrukturyzowanego przeglądu poszczególnych teorii na rzecz, jak autorka sama pisze, „połączenia tekstów, tematów, pojęć i teorii tak, by przyczyniło się to do powstania zasobu wspólnej wiedzy, przekracza-

\footnotetext{
1 Por. np. Kulturo-znawstwo. Dyscyplina bez dyscypli$n y$ ?, red. W. J. Burszta i M. Januszkiewicz, Warszawa 2010; J. Kmita, Późny wnuk filozofii. Wprowadzenie do kulturoznawstwa, Poznań 2007.

2 Zob. np. J. Kmita, op. cit.; E. Baldwin (i in.), Wstęp do kulturoznawstwa, Poznań 2007; Ch. Barker, Studia kulturowe. Teoria i praktyka, Kraków 2005; Perspektywy refleksji kulturoznawczej, red. J. Sójka, Poznań 1995; Kulturo-znawstwo. Dyscyplina bez dyscypliny?, op. cit.

3 M.in. Pamięć zbiorowa i kulturowa. Wspótczesna perspektywa niemiecka, red. M. Saryusz-Wolska, Kraków 2009; A. Assmann, Między historią a pamięcią. Antologia, Kraków 2013.
} 
jącego granice dyscyplin i metod, a więc prób[y] stworzenia kulturoznawczej podstawy"4. Rozważania autorki oscylują wokół siedmiu podstawowych zagadnień kulturoznawczych: znaków, mediów, ciała, czasu, przestrzeni, pamięci i tożsamości, przy czym kolejność tych punktów nie jest przypadkowa. Jak słusznie zauważają tłumaczki przekładu na język polski, Anna Artwińska i Katarzyna Różańska, układ rozdziałów ma poniekąd charakter chronologiczny: od refleksji o znakach, występujących już w kulturach przedpiśmiennych, autorka przechodzi do problematyki związanej z mediami, $\mathrm{w}$ tym m.in. $\mathrm{z}$ autorstwem - przywołuje tu przykłady z literatury średniowiecznej i renesansowej. Dociekania na temat ciała, czasu i przestrzeni, zawarte w kolejnych rozdziałach, są u Assmann związane przede wszystkim z wiekami XIX i XX ${ }^{5}$, zaś refleksje o pamięci i tożsamości prowadzą czytelnika ku dyskursom bardzo współczesnym, związanym z pamięcią w kontekście drugiej wojny światowej, z migracją czy poszukiwaniem własnej tożsamości $\mathrm{w}$ dobie globalizacji ${ }^{6}$. Assmann, jako literaturoznawczyni, decyduje się na zilustrowanie problematyki wymienionych kompleksów tematycznych za pomocą przykładów z literatury, przede wszystkim anglojęzycznej. Opisując więc konkretne problemy badawcze, zawsze podpiera się wybranym tekstem literackim i za jego pomocą uzmysławia czytelnikowi istotę danej kwestii. Skanonizowane na przestrzeni wieków teksty literackie pojmuje przy tym autorka jako swoisty element - czy też fenomen - kultury. Assmann proponuje poddanie go historycznej rekontekstualiza-

\footnotetext{
4 A. Assmann, Wprowadzenie do kulturoznawstwa. Podstawowe terminy, problemy, pytania, tłum. A. Artwińska i K. Różańska, Poznań 2015, s. 5.

5 Acz nie tylko, bo wspomniana chronologia zostaje od czasu do czasu przełamana.

6 Por. A. Artwińska, K. Różańska, Kulturoznawstwo Aleidy Assmann, [w:] A. Assmann, Wprowadzenie..., s. 11-28 , tu s. 19.
}

cji, co, jej zdaniem, stanowi istotne zadanie kulturoznawstwa ${ }^{7}$.

Polski przekład rozpoczyna się od autorskiej przedmowy do trzeciego wydania książki. Po niej następuje obszerny, wnikliwy wstęp do pracy autorstwa tłumaczek, zatytułowany Kulturoznawstwo Aleidy Assmann. Jego drobiazgowość jest zarówno jego mocną, jak i słabą stroną, bowiem o ile autorki bardzo przejrzyście przybliżają sylwetkę Aleidy Assmann, zainteresowania badawcze jej oraz Jana Assmanna, jak również prezentują specyfikę ich sposobu podejścia do kulturoznawstwa, to jednak szereg poruszonych aspektów zaledwie kilka stron dalej, we wstępnym rozdziale swojej pracy (pt. Definicje kultury), omawia sama autorka dzieła. Jawi się to więc jako nieco zbędne „mnożenie bytów” - ale dla adeptów kulturoznawstwa być może przydatne. Tłumaczki w niezwykle szczegółowy sposób opisują także układ i konstrukcję książki, aż po skrupulatne streszczenie każdego $\mathrm{z}$ rozdziałów (a nawet wstępu Aleidy Assmann, który sam w sobie ma charakter wprowadzający i objaśniający strukturę podręcznika). Wstęp Artwińskiej i Różańskiej to więc od razu niemal streszczenie zapowiadanej pozycji, jej interpretacja i recenzja. Autorki same wskazują nawet na potencjalne zarzuty wobec pracy Assmann, a za pomocą owego refutatio poniekąd odbierają recenzentom część ich zadania. Jest to więc wstęp napisany w bardzo klarowny i przyjazny dla

\footnotetext{
7 Perspektywę Assmann, jako kulturo-, ale i literaturoznawczyni, należy również widzieć w kontekście tzw. kulturowego zwrotu teorii, który, jak pisze Anna Burzyńska, „[p]rzyniósł teorii literatury konieczne i pożądane otwarcie na całość praktyk uniwersum kulturowego, z którymi w oczywisty sposób powiązane są również praktyki pisania i czytania”. „Zwrot ten znacznie poszerzył przede wszystkim horyzonty interpretacji, uruchamiając zróżnicowane konteksty kulturowe, w jakich uczestniczy tekst literacki”, konkluduje dalej Burzyńska (A. Burzyńska, Kulturowy zwrot teorii, [w:] Kulturowa teoria literatury. Główne pojęcia i problemy, red. M. P. Markowski i R. Nycz, Kraków 2010, s. 41-91, tu s. 87).
} 
czytelnika sposób, lecz jednocześnie nadto drobiazgowy. Zbyt mało przestrzeni pozostawia on na refleksję i interpretację czytelnika, za dużo aspektów powtarza się potem we wstępie autorskim.

Po wprowadzeniu tłumaczek następuje zwięzła i precyzyjna Nota redakcyjna i uwagi tlumaczek. Trzeba tu podkreślić bardzo dobry językowo przekład całości tekstu i dbałość o detale wydania pracy Assmann ${ }^{8}$. Ponadto należy docenić, iż inaczej niż w oryginalnej wersji przypisy zawarte w polskim przekładzie uzupełnione zostały o pełną informację bibliograficzną, co zdecydowanie ułatwia czytelnikowi zidentyfikowanie szukanej pozycji. Znakomitym pomysłem było też uzupełnienie dołączonej do każdego rozdziału przez Assmann wybranej literatury przedmiotu o propozycje dotyczące bibliografii w języku polskim. Zwiększa to jeszcze dodatkowo użyteczność podręcznika dla studentów polskich.

Kolejny punkt książki stanowi wstęp autorski, zatytułowany Definicje kultury. Assmann zwięźle, acz precyzyjnie wyjaśnia, jaki jest cel i układ jej Wprowadzenia..., a następnie przechodzi do wstępnych rozważań na temat kultury. Autorka wychodzi przy tym od sześciu podstawowych definicji kultury, rozumianej jako: 1) pielęgnacja, 2) twór geograficzno-polityczny, 3) całokształt działalności ludzkiej, 4) kultura wysoka, 5) cywilizacja, 6) kultura rozumiana krytycznie jako auratyczna ${ }^{9}$ alternatywa dla rzeczywistości („szkoła frankfurcka”) ${ }^{10}$, by następnie przekonująco uzasadnić rację bytu kulturoznawstwa. Badaczka podkreśla przy

8 W całej pracy znaleźć można jedynie kilka tzw. literówek, jak np. „Elliot” (zamiast „Eliot”) na s. 213 czy „dotyczą cych” (zamiast: „dotyczących”) na s. 23.

9 Autorki przekładu używają tutaj określenia „pełen aury”, tłumacząc zapewne niemieckie słowo „auratisch”. Jednak w odniesieniu do pojęcia „aury”, stworzonego przez Waltera Benjamina, celniejsze byłoby użycie określenia „auratyczny”.

10 Por. A. Assmann, Wprowadzenie..., s. 31-38. tym swoją tezę, iż kulturoznawstwo „nie powstało w wyniku kolejnej m(et)ody czy zwrotu teoretycznego, lecz jako odpowiedź na gruntowną przemianę społeczeństwa i (nie)porządek naszego świata" ${ }^{11}$. Assmann przyznaje wprawdzie, że przedmiot badań kulturoznawstwa jest „rozproszony”, jednak pytania badawcze tej dyscypliny postrzega autorka jako bardzo precyzyjne. Mają się one interesować i zajmować tym, „jak to, co stworzył człowiek, a więc kultura, zostało zrobione, to znaczy w jakich warunkach, przy pomocy jakich podejść, w jakim celu i z jakimi konsekwencjami” ${ }^{12}$. W ostatnim podrozdziale swojego wstępu autorka pokazuje dwie odmienne drogi do powstania kulturoznawstwa jako dyscypliny akademickiej, omawiając najważniejsze różnice pomiędzy niemieckim kulturoznawstwem (Kulturwissenschaft) a angielskimi (i amerykańskimi) cultural studies.

W pierwszym rozdziale swojej pracy Assmann koncentruje się na znakach, które - używane przez człowieka celem zapamiętywania i przekazywania wiedzy - stanowią podstawową cechę odróżniającą go od zwierzęcia. Wychodząc od tej antropologicznej perspektywy, autorka przywołuje następnie podstawowe teorie i koncepcje znaków językowych. Przechodzi więc od klasycznej, strukturalistycznej definicji znaków językowych Ferdinanda de Saussure'a ${ }^{13}$, poprzez poststrukturalistyczną krytykę statycznej koncepcji znaków Jacques’a Derridy i Ludwiga Jägera $^{14}$, aż po schematy funkcji znaków

\footnotetext{
11 Ibidem, s. 39.

12 Ibidem, s. 41.

13 Według de Saussure'a znak językowy to zawsze kompleks składający się z elementu znaczącego i elementu znaczonego.

14 Według Jägera znaki (i słowa) nie posiadają żadnego raz na zawsze określonego znaczenia, lecz zawsze dopiero je uzyskują w konkretnej sytuacji komunikacyjnej.
} 
Karla Bühlera ${ }^{15}$, Jana Mukařovskiego ${ }^{16}$ i Romana Jakobsona ${ }^{17}$. Assmann pokazuje w ten sposób, jak na przestrzeni wieków zmieniało się podejście do kwestii języka i słowa (podkreśla przy tym m.in. narodziny konstruktywizmu i tzw. linguistic turn około roku 1900), by w kolejnych podrozdziałach na przykładach literackich uwidocznić najbardziej charakterystyczne zaburzenia w komunikacji międzyludzkiej. Autorka wskazuje przy tym, że język z jednej strony jest podstawowym środkiem cywilizowania człowieka, ale $\mathrm{z}$ drugiej - łatwo może stać się również sposobem jego dyscyplinowania i zdominowania, a nawet posłużyć jako narzędzie przemocy.

Refleksja na temat znaków i języka prowadzi autorkę do rozważań o mediach, zawartych w rozdziale drugim. Przez media Assmann rozumie zarówno materialne nośniki znaków (węższe znaczenie), jak i wszelkie formy pośrednictwa pomiędzy człowiekiem a światem, a więc podstawę ludzkiej komunikacji na świecie (znaczenie szersze). Autorka podkreśla przede wszystkim konstruktywny charakter mediów, które nie przedstawiają rzeczywistości, lecz ją kreują, kształtują, tworzą. Zakładając medialność wiedzy kulturowej, Assmann pokazuje, jak istotna jest różnica pomiędzy kulturami oralnymi a piśmiennymi. O ile bowiem w spoleczeństwach oralnych istotne są techniki zapamiętywania najważniejszych treści, polegające przede wszystkim na powtarzaniu, mnemotechnikach i przedstawianiu (podczas silnie zrytualizowanych świąt), to pismo umożliwia człowiekowi zachowanie określonych treści i wiadomości

\footnotetext{
15 Bühler wyróżnił trzy funkcje języka: przedstawieniową, ekspresywną i apelatywną.

${ }^{16}$ Mukařovský rozszerzył schemat Bühlera o funkcję estetyczną.

17 Jakobson do schematu Bühlera i Mukařovskiego dodał jeszcze funkcję fatyczną, odnoszącą się do kanału komunikacyjnego i mającą za zadanie utrzymanie (a najpierw stworzenie) kontaktu między nadawcą a odbiorcą.
}

w sposób niezależny od pamięci ${ }^{18}$. Ponadto autorka dość szeroko omawia ściśle związaną z tematem mediów problematykę autorstwa. Wychodzi tutaj od różnic pomiędzy często anonimowymi autorami słabymi, pozostającymi w cieniu autorytetów, patronów czy fundatorów, a autorami silnymi, pewnymi własnej mocy twórczej indywidualnościami, kojarzonymi $\mathrm{z}$ geniuszem. Udowadniając, że w XVIII i XIX wieku rozróżnienie to wyraźnie odpowiadało różnicy płci - kobiety z reguły należały do autorstwa słabego, z zasady wykluczonego z literackiego kanonu, zaś mężczyźni do autorstwa silnego ${ }^{19}$ - Assmann sygnalizuje tematykę kolejnego rozdziału swojej pracy, poświęconego problematyce związanej z ciałem, ale i właśnie z płciowością. Najpierw jednak wraca jeszcze do autorstwa, ukazując, jak ów kult (męskiego) geniusza i silnego autora zaledwie jednym krótkim manifestem, zatytułowanym Śmierć autora, w 1968 roku obalił Roland Barthes. Omawiając na koniec rozdziału „zwrot ikoniczny” (iconic turn) z przełomu XX i XXI wieku, badaczka wskazuje, że w naszej kulturze dokonuje się współcześnie nie tyle przejście od (medium) tekstu do (medium) obrazu (jak to widział amerykański inicjator iconic turn W. J. T. Mitchell ${ }^{20}$ ), lecz że mamy do czynienia $\mathrm{z}$ „produktywną interakcją tych sys-

18 Także tutaj Assmann, wykazując się niezwykłą erudycją, prezentuje i interpretuje stare teksty literackie tematyzujące m.in. problemy dawnych kopistów.

19 We właściwy sobie sposób autorka okrasza swoje tezy obrazowymi komentarzami z literatury, gdy w tym kontekście przywoluje np. Oskara Wilde’a: „Żadna kobieta nie jest geniuszem. Kobieta jest rodzajem dekoratywnym. Nigdy nie ma nic do powiedzenia, ale to nic wypowiada czarująco. Kobieta oznacza triumf materii nad umysłem, jak mężczyzna triumf umysłu nad moralnością" (O. Wilde, Portret Doriana Graya (1890), tłum. M. Feldmanowa, Kraków 1995, s. 40. Cyt. za: A. Assmann, Wprowadzenie..., s. 121 i n.).

20 Zob. m.in. jego prace: W. T. J. Mitchell, What Do Pictures Want?: The Lives and Loves of Images, Chicago 2005; idem, Image Science: Iconology, Visual Culture and Media Aesthetics, Chicago 2015. 
temów znaków" ${ }^{\text {21 }}$. Przekonuje ponadto, że ów trend do intermedialności, ale także w nauce - do interdyscyplinarności i przekraczania granic poszczególnych dziedzin, może być działaniem produktywnym i kreatywnym ${ }^{22}$.

O ile zatem w dwóch pierwszych rozdziałach autorce chodzi o podkreślenie medialnego charakteru samej kultury, która zawsze wymaga jakichś materialnych form prezentacji, oraz o pokazanie rozwoju poszczególnych systemów znaków i form medialnych na przestrzeni wieków, to w kolejnym rozdziale koncentruje się ona na zagadnieniach dotyczących dyskursów na temat ciała i cielesności, nie zapominając przy tym o problematyce gender. $\mathrm{Za}$ pomocą rozlicznych przykładów z literatury pięknej Assmann pokazuje, jak ciało było postrzegane na przestrzeni wieków, precyzuje też podstawowe konteksty dla problematyki ciała i cielesności: ciało $\mathrm{w}$ odniesieniu do mediów, w odniesieniu do perspektywy gender czy ciało a jego sprawczość (agency). W swoich rozważaniach autorka wychodzi od ujęcia ciała jako podstawy wszelkiego poznania (zmysły jako najważniejsze organy postrzegania $)^{23}$ oraz od analizy hierarchii zmysłów na przestrzeni dziejów. W dalszej części rozdziału badaczka koncentruje się na zagadnieniach związanych $\mathrm{z}$ cielesnymi tabu, konfrontuje się z seksualnością jako tematem literackim i omawia pokrótce problematykę ról płciowych (gender). Pokazuje też sposoby, w jakie kultura zwykła dyscyplinować (i kreować) ciało, na ko-

\footnotetext{
21 A. Assmann, Wprowadzenie..., s. 138.

22 Rzecz jasna, intermedialność pojawia się u Assmann także jako temat literacki. Przywołuje ona m.in. powieść Adam Bede George Eliot (1859), opowiadanie Autentyk Henry'ego Jamesa (1893) czy Pannę w ogrodzie Antoniny S. Byatt (1978).

${ }_{23}$ Perspektywa Assmann jest w tym sensie stricte fenomenologiczna - zmysły są tutaj ważnym elementem, poprzez który człowiek (bezzałożeniowo) poznaje i odbiera świat zewnętrzny.
}

niec zaś skupia się na kwestii kultury ekskarnowanej (niezmysłowej) i inkarnowanej (zmysłowej).

W kolejnym rozdziale Assmann przechodzi do rozważań na temat czasu, który - jako kulturoznawca - postrzega jako kulturowy konstrukt i nośnik znaczeń, służący przede wszystkim orientacji. Zgodzić się tu należy z tłumaczkami, Artwińską i Różańską, iż godna uwagi jest w tej części książki lekkość i swoboda, z którą autorka prowadzi czytelnika przez meandry różnorakich kulturowych wyobrażeń i inscenizacji czasu na przestrzeni dziejów. Czas jako problem badawczy już wcześniej mocno zajmował Assmann - w 2013 roku opublikowała ona obszerną pracę, poświęconą wyłącznie problematyce związanej z relacją człowieka do $\mathrm{czasu}^{24}$. We Wprowadzeniu... autorka poddaje refleksji kulturowe postawy odczuwania czasu (pisze o ambiwalencji czasu, o czasie życia, analizuje tzw. kultury „gorące” i „zimne”, wspomina o zmianie pokoleniowej i o przyspieszeniu czasu od końca XVIII wieku), by następnie przejść - zgodnie z przyjętym schematem - do prezentacji literackich inscenizacji tematu. Tym razem, poza przywołaniem literackich obrazów i metafor czasu, Assmann przeprowadza także analizę poszczególnych schematów narracyjnych, gatunków i form poetyckich. Rozdział kończy się refleksją na temat koszmaru historii i prób przezwyciężania czasu, przeprowadzoną $\mathrm{w}$ oparciu o fragmenty Ulissesa Jamesa Joyce’a i poezję T. S. Eliota.

„Podczas gdy modernizm uprzywilejował czas, postmodernizm zainteresował się przestrzenią, stwierdza autorka, i słowa te pozwalają jej płynnie przejść $\mathrm{z}$ rozdziału dotyczącego czasu do kulturoznawczych rozważań na temat przestrzeni ${ }^{25}$. Tzw. zwrot

\footnotetext{
24 A. Assmann, Ist die Zeit aus den Fugen? Aufstieg und Fall des Zeitregimes der Moderne, München 2013.

25 Eadem, Wprowadzenie..., s. 221.
} 
przestrzenny (spacial turn) sprowokował zainteresowanie kategorią przestrzeni jako drugą, poza czasem, istotną współrzędną ludzkiego funkcjonowania $\mathrm{w}$ świecie ${ }^{26}$. Assmann podkreśla, jak bardzo obie te kategorie związane są z postrzeganiem człowieka, uwarunkowanym przez możliwości i ograniczenia jego ciała. Poza tym antropologicznym ujęciem, autorka przywołuje następnie inne perspektywy dotyczące przestrzeni, w tym socjologiczne, polityczne, historyczne, a także kategorię międzyprzestrzeni. W kolejnych podrozdziałach, opierając się na przykładach literackich, Assmann szczegółowo analizuje konkretne typy przestrzeni. I tak, analizie poddany zostaje Londyn jako przestrzeń doznań, jako przestrzeń działania oraz jako przestrzeń postrzegania ${ }^{27}$. Następnie zaś badaczka przechodzi do kwestii związanych z centrum i peryferiami oraz do przestrzeni mitycznych. Przestrzeń mityczna i odpowiednio dobrane przykłady literackie prowadzą autorkę w kierunku rozważań o powrotach do korzeni, o poszukiwaniu i odnajdywaniu tożsamości oraz o obchodzeniu się z pamięcią. To już stanowi zapowiedź dwóch ostatnich rozdziałów.

Pamięć i tożsamość to $\mathrm{w}$ ostatnich dziesięcioleciach nośne i aktualne tematy; to na tym obszarze ogniskują się również dominujące zainteresowania badawcze samej autorki ${ }^{28}$. W rozdziale szóstym dokonu-

26 Jak pisze też Assmann, rosyjski literaturoznawca Michaił Bachtin powiązał obie te kategorie (czas i przestrzeń) i stworzył termin „chronotop”, czyli „czasoprzestrzeń”. Zob. M. Bachtin, Formy czasu i czasoprzestrzeni w powieści, [w:] idem, Problemy literatury i estetyki, Warszawa 1982, s. 278-488.

27 Z literatury Assmann przywoluje tutaj Thomasa de Quinceya, Johna Gaya, Virginię Woolf czy Edgara Allana Poego.

${ }_{28}$ Zob. m.in. A. Assmann, Das neue Unbehagen an der Erinnerungskultur. Eine Intervention, München 2013; eadem, Geschichte im Gedächtnis. Von der individuellen Erfahrung zur öffentlichen Inszenierung, München 2007; eadem, Der lange Schatten der Vergangenheit. Erinnerungskultur und Geschichtspolitik, München 2006; je ona bardzo przejrzystego uporządkowania poszczególnych terminów i pojęć oraz dyskursu dotyczącego pamięci. Rozróżnia więc pamięć (Gedächtnis) i wspomnienie (Erinnerung) 29 , pamięć aktywną od pasywnej, epizodyczną od semantycznej czy wreszcie - pamięć indywidualną od zbiorowej. Nie zapomina także o ściśle związanym $\mathrm{z}$ kategorią pamięci pojęciem traumy, która może być w społeczeństwach przekazywana z pokolenia na pokolenie. Jako nieodzowny przykład literacki zostaje przywołany Hamlet, którego Assmann w fascynujący sposób odczytuje na nowo właśnie przez pryzmat współwystępujących w dramacie różnych typów pamięci.

Przechodząc do kończących Wprowadzenie... dyskursów o tożsamości, autorka pokazuje, jak bardzo pamięć wiąże się z konstruktami tożsamościowymi. Punktem wyjścia jest tutaj kilka uwag natury ogólnej i podstawowej, typu: jak i kiedy wyłoniło się zainteresowanie problemem tożsamości indywidualnej, co formalnie służy wyznaczaniu tożsamości indywidualnej etc. Autorka dzieli rozdział na cztery podrozdziały. $\mathrm{W}$ dwóch pierwszych omawia zagadnienia związane $\mathrm{z}$ tożsamością indywidualną (osoba, podmiot, płeć, tożsamość inkluzji i ekskluzji, kwestia sobowtóra czy tzw. tożsamości zwielokrotnionej) i z tożsamością zbiorową (etniczność, naród, kultura). W trzecim podrozdziale Assmann pokazuje, jak żywo różne aspekty tożsamości zbiorowej i indywidualnej dotyczą współczesnego człowieka. Jednym z takich aspek-

eadem, Erinnerungsräume. Formen und Wandlungen des kulturellen Gedächtnisses, München 1999; A. Assmann, U. Frevert, Geschichtsvergessenheit - Geschichtsversessenheit. Vom Umgang mit deutschen Vergangenheiten nach 1945, Stuttgart 1999.

29 Pokazuje przy tym także specyfikę języka angielskiego, w którym - inaczej niż w języku niemieckim - na określenie zarówno „pamięci”, jak i „wspomnienia” występuje jedno słowo memory. Za nim kryć się jednak może cały repertuar znaczeń. Por. A. Assmann, Wprowadzenie..., s. 263. 
tów są nierozdzielnie związane $\mathrm{z}$ polityką tożsamościową spory o kanon - bo to o ów „sztandar”, dzięki któremu poszczególne społeczeństwa „ustanawiają swój rodowód, określają tożsamość i prezentują się świa$\mathrm{tu}^{\prime 30}$, toczą się nieodmiennie gorące spory. Są one tak intensywne, gdyż bezpośrednio odnoszą sią do zdefiniowania, kim - jako społeczeństwo, jako naród - jesteśmy, i z jakimi wartościami chcemy się utożsamiać. Są to więc nadrzędne dyskursy, mające ogromny wpływ na kształt edukacji i wartości społecznych, dlatego też budzą gwałtowne emocje $^{31}$. Jako interesujący przykład konfrontacji $\mathrm{z}$ kanonem Zachodu Assmann przywołuje karaibską pisarkę Jamaicę Kincaid. Jest to zarówno ilustracja zastosowania tekstów z zachodniego kanonu jako narzędzia władzy i przemocy wobec dziewczynki wychowanej na karaibskiej wyspie, jak i poszukiwania tożsamości indywidualnej oraz własnej odrębności przez młodą bohaterkę, do czego impuls paradoksalnie daje właśnie zetknięcie się z owym zachodnim kanonem tekstów. Rozdział o tożsamości(ach), a zarazem całe Wprowadzenie... Assmann, kończy się rozważaniami na temat „wędrowców między kulturami”. Także tutaj autorka konsekwentnie opiera się na literaturze i ilustruje swoje rozważania dziełami Mary Antin, Josepha Conrada i Salmana Rushdiego.

Po opublikowaniu w 2013 roku w Polsce antologii prac Assmann Między historia a pamięcią ${ }^{32}$, polski przekład

30 H. Lindenberger, The History in Literature: On Value, Genre, Institutions, New York 1990, s. 2. Cyt. za: A. Lanoux, Od narodu do kanonu. Powstawanie kanonów polskiego i rosyjskiego romantyzmu w latach 1815-1865, thum. M. Krasowska, Warszawa 2003, s. 18.

31 Zob. na ten temat m.in. P. Lauter, Canons and Contexts, New York 1991; H. Bloom, The Western Canon. The Books and School of the Ages, New York 1995; Hierarchie, kanony, wartości. Z Adamem Czerniawskim rozmawia Piotr Wilczek, „Opcje” 2001, nr 5 (40), s. 34; J. Prokop, Kanon literacki i pamięć zbiorowa, [w:] idem, Lata niby-Polski, Kraków 1998.

32 A. Assmann, Między historia a pamięcia...
Wprowadzenia... jest kolejnym krokiem przybliżającym postać i badania tej wybitnej niemieckiej kulturo- i literaturoznawczyni polskiemu czytelnikowi. Już sam ten fakt zasługuje na uznanie. Mocną stroną podręcznika jest zrozumiały, potoczysty język oraz bezpośrednie odniesienie teorii kulturoznawczych do praktyki. Wyjątkowa erudycja autorki każe jej posługiwać się przy tym mnogością najróżniejszych odniesień intertekstualnych, zaś same teksty literackie to dla badaczki swoisty impuls do refleksji zdecydowanie wykraczającej poza samo dzieło literackie. Assmann pokazuje też, że błędem kulturoznawstwa jest zbytnie koncentrowanie się na sztuce czy kulturze popularnej w jej oczach celem tej dyscypliny jest omawianie historii literatury oraz kanonicznych dzieł literackich z nowej perspektywy, jako specyficznych fenomenów kulturowych.

Momentami wywód Assmann sprawia wrażenie nieco chaotycznego: wspomniana wielość przykładów literackich to z jednej strony ogromny atut tej pracy, ale z drugiej - chwilami trudno nadążyć za właściwym tokiem myśli autorki, skłonnej do częstej dygresji i przywoływania co rusz nowych intertekstualnych odniesień do postaci, wydarzeń, literatury etc. Nie ułatwia tego także struktura książki, w której rozdziały zostały podzielone na podrozdziały, te zaś na jeszcze mniejsze całości.

Kulturoznawstwo Aleidy Assmann ma specyficzny charakter. Jako pasjonatka literatury (zwłaszcza anglojęzycznego kręgu kulturowego) to przede wszystkim na dziełach literackich i na ich nowych odczytaniach opiera ona swoje badania $w$ tej dziedzinie. Nie można jednak zapomnieć, że choćby zagadnienia związane $\mathrm{z}$ czasem w ujęciu kulturoznawczym można by równie dobrze badać na przykładzie innych dziedzin sztuki czy choćby rytuałów pogrzebowych na przestrzeni wieków, zaś kwestie ciała - przykładowo na podstawie 
sposobu ubierania się człowieka. Dlatego Wprowadzenie... Assmann adepci kulturoznawstwa z pewnością powinni studiować równolegle z lekturą innych wstępów do tej dziedziny wiedzy. Pozycja tej niemieckiej badaczki to bowiem tylko jedno - acz fascynujące - z możliwych podejść badawczych $\mathrm{w}$ tej dyscyplinie. W żadnym wypadku nie jest to zarzutem - praca ta stawia sobie po prostu (jasno) sprecyzowane cele i wyznacza określone punkty ciężkości.

Dużym atutem podręcznika, szczególnie dla studentów, będzie z pewnością zwięzłe podsumowanie, zawarte na końcu każdego rozdziału. Ułatwia ono czytelnikowi orientację oraz pomaga wyłuskać z wywodu Assmann najistotniejsze treści. Ponadto, choć należy uszanować i docenić przyjętą konwencję posługiwania się wyłącznie przykładami $\mathrm{z}$ obszaru literatury anglojęzycznej, wśród niektórych czytelników z pewnością zrodzi się w trakcie lektury oczekiwanie, by Assmann, która jest bardzo aktywną komentatorką i znawczynią również literatury niemieckojęzycznej, choćby w kilku przykładach oparła się także na ka- nonicznych tekstach kultury niemieckiego obszaru językowego. Zwłaszcza germaniści z pewnością doceniliby ten fakt. Z drugiej strony, przyjęta konwencja pozostaje w pełni zrozumiała, wynika $\mathrm{z}$ fascynacji autorki literaturą anglojęzyczną i dodatkowo czyni podręcznik szczególnie atrakcyjną propozycją dla filologów angielskich.

Praca Assmann to na niemieckich uniwersytetach dzieło słusznie należące już do kanonu kulturoznawczego. Odbiorcami Wprowadzenia... są tam nie tylko stricte kulturoznawcy, ale również humaniści innych dziedzin - filolodzy, historycy, historycy sztuki, etnolodzy czy socjolodzy. To zresztą było intencją samej autorki, dla której przekraczanie granic własnej dyscypliny i korzystanie w pracy badawczej z dorobku innych nauk zawiera zawsze potencjał twórczy. Sposób uprawiania nauki przez nią samą jest tego znakomitym przykładem.

Aleida Assmann, Wprowadzenie do kulturoznawstwa. Podstawowe terminy, problemy, pytania, tłum. i wstęp Anna Artwińska i Katarzyna Różańska, Wydawnictwo „Nauka i Innowacje”, Poznań 2015, 363 ss. 